\title{
Impact of Covid-19 in the European Start-ups Business and the Idea to Re-energise the Economy
}

\author{
Stavros Kalogiannidis ${ }^{1} \&$ Fotios Chatzitheodoridis ${ }^{1}$ \\ ${ }^{1}$ Department of Regional and Cross Border Development, University of Western Macedonia, Greece \\ Correspondence: Stavros Kalogiannidis, Department of Regional and Cross Border Development, University of \\ Western Macedonia, Greece.
}

Received: October 6, 2020

Accepted: November 4, 2020

Online Published: January 11, 2021

doi:10.5430/ijfr.v12n2p55

URL: https://doi.org/10.5430/ijfr.v12n2p55

\begin{abstract}
This paper has been constructed with the aim to evaluate the profound Impact of Covid-19 in the European start-ups business as well as to illustrate certain effective ideas in order to re-energise the economy. The sudden arrival of this deadly pandemic has impacted the overall world in many different ways and economy is one of them. Therefore, through the execution of secondary research, this study is going to assess the distinctive notions of economic downfall in the context of European countries and different industries of this continent. In the last decade start-ups have generated a lot of employment. Start-ups have found new markets and opportunities that have revolutionised the way business has been perceived. The titans of commerce and various industries have been left behind by smart innovation and sheer brilliance. So it is only natural that there should be more scrutiny on the impacts of the Corona pandemic on the start-up industry. The impact of the Covid-19 pandemic on the start-up industry should be carefully studied in order to make more informed policies. The aim of this paper is to study the impact of Covid-19 on the start-up industry of the European Union. This paper will also make an in depth study of the strategic remedies employed by various governments re energise the sector.
\end{abstract}

Keywords: start-ups, innovation, industry, mitigating measures, European Union

JEL Classification: O31

\section{Introduction}

\subsection{Research Background}

Start-ups have come to be the most important driving force of economic growth in the last decade. Start-ups have been known to be innovative and capable of interrupting the usual way of business. The covid 19 pandemic has left a devastating economic scene in its path. The start-up business has also not been spared. The economic scene in Europe is just like the rest of the world, bleak. The worst recession is there since the Second World War. The GDP in the 27 members of the European Union has seen a sharp decline by 11.9 percent as suggested by Chinn et al., (2020). On the other hand, the countries which use the Euro as a currency have seen their GDP being contracted by 12.1 percent in the first quarter of 2020. Germany, Europe's biggest economy, has seen a 10 percent decline in their GDP. Unemployment has risen at an alarming rate. France has seen a 13.8 percent decline in their GDP. Italy recorded a 12.4 percent drop in their GDP while Spain's GDP was contracted by 18.4 percent. In this grim and alarming situation, the start-ups in Europe also haven't been doing well. It has been reported that almost 49 percent of the start-up companies have sought government aided loans from the banks as mentioned by Brown et al., (2020). Different governments of different countries have announced various stimulus packages to revitalise their country's economy. This paper intends to take an in-depth look at the impact of Covid-19 on European economy emphasising on the start-up industry and remedial initiatives undertaken by governments and other concerned bodies.

\subsection{Research Objectives}

- To evaluate the effects of the Covid-19 pandemic and the worldwide shutdown on the start-up business operating from Europe.

- To evaluate the mitigating measures taken by the governments to revitalise the economies.

- To evaluate the innovative ideas that might help the start-up industry recover faster. 


\subsection{Research Questions}

- What are the devastating effects of the Covid-19 pandemic and the worldwide shutdown on start-up business operating from Europe?

- What are the mitigation measures taken by the government to revitalise the economies?

- What are some of the best innovative ideas to help the European industry recover faster?

\subsection{Significance of Research}

As it has been reported and documented that the start-up businesses have been responsible for a substantial amount of growth of the economies in the recent years. It is imperative that this promising sector should be paid more attention and gets all the necessary help to get back on its feet as soon as possible. A lot of people depend on this industry for their livelihood. In this context, the help will be more effective if it's thoroughly thought out. The more studies are done on this topic, the more materials for policy makers to base their policies on.

\section{Literature Review}

\subsection{Effects of Coronavirus on the European Start-up Industry}

The aftermath of the corona pandemic has been devastating. 43 percent of the European start-ups have frozen their hiring process. A survey has revealed that 40 percent of the start-up companies are expecting to see their revenue drop by 25 percent in 2020 as mentioned by Arundale and Mason (2020). This survey was conducted by LocalGlobe and Dealroom. There were about 140 participants in this survey. About half of the respondents were either from France or from Germany. It has been recorded that more than half of the respondent start-ups were formed in the last five years. Almost one third of the respondents companies have decided to make some layoffs permanently while 17 percent of the respondents said they might lay off 10 percent of their current work force. There are over 18,000 start-ups in Europe competing for a bigger share of the markets as suggested by Donthu and Gustafsson (2020). These companies can be divided into four categories keeping in mind their vulnerabilities.

1. Start-ups that have had a positive effect on the business due the pandemic (Food delivery, grocery delivery, health related start-ups, video calling applications etc.).

2. Start-ups that have been putting in a good fight (gaming start-ups, streaming start-ups etc.).

3. Start-ups that have been affected (lending start-ups, fashion start-ups etc.)

4. Start-ups that have been severely affected (travel related or mobility related start-ups).

Each category listed above has its own set of challenges and opportunities. For the start-ups related to logistics and healthcare or video conferencing platforms have to keep with the burgeoning demands without compromising quality of the product or services rendered. Managing rapid growth is going to be its prime challenge. The companies belonging to the middle category are the highest in numbers. They will have to face operational trouble. The start-ups which have been severely affected could see their revenue plummeting to zero. The number of start-ups which succeed is always less than the ones which fail. It is inevitable that some start-ups will decrease in valuation.

European start-ups have been estimated to have given more than 2 million jobs in 2019. There are 290,000 people in London who work for start-ups while 100,000 people in Paris are employed by start-ups as suggested by Alonso et al., (2020). The number of people working for start-ups in Berlin is 78,000. Amerstardam is reported to have 48 jobs in start-up companies per a 1000 people while in Stockholm it is 38 per 1000. Across Europe every year there has been a 10 percent growth in job creation until 2020 Kalogiannidis et al.,(2020)

\subsection{The Mitigation Measures Taken by the Government to Revitalise the Economies}

Successfully building and structuring a start-up is considered very critical in the pandemic situation of Covid-19 as there is a global pandemic shutting down the economy across the world. Most of the business, especially the European start-up industry has faced downfall due to this situation. There are some effective strategies, such as renegotiation with supplier contracts, reviewing online subscription, recognising new demands, brainstorming survival strategies, applying for government grants, reviewing business models, calling key partners, offering remote services, and so on. According to Kashyap and Raghuvanshi (2020), among them, government grants as a prevention strategy would help restructure the business related to European start-ups as stated below.

\subsubsection{Government's Stimulus Packages as a Prevention Strategy}

At the end of May this year the European Commission proposed a stimulus package of 750 billion euro, as a prevention strategy that would help in restructuring the business. The commission has also come with a plan called Next 
Generation EU Recovery Plan or strategy to mitigate the disastrous effects left by the Corona pandemic. This strategy hopes to encourage investment in a green and responsible, resilient European economy. Out of this 750 billion, 390 billion euro has been decided to be used as grants. Along with this package countries have individually announced stimulus packages. Germany has announced a 130 billion package euro to revamp the economy as mentioned by Kuckertz et al., (2020). France has announced a hundred billion euro stimulus package. On the other hand the Italian govt. has decided to spend 55 billion euro to re launch their economy.

\subsection{Innovative Ideas to Help the European Industry Recover Faster}

The Covid-19 pandemic has forced the start-up companies to adopt some significant changes. The recently established ventures and the ones which have been in the market for some years, both have been adapting to these new changes. A few start-ups situated in the EU have already changed the nature of their product in order to meet the new demand of the customer. France has even put together a fund of 4 billion euro to support their start-ups. Start-up companies have always taken more risk than other companies as mentioned by Kashyap and Raghuvanshi (2020). They capitalise on innovation and brilliance. They are more adept at adjusting to new situations because they handle change very well. In this premise the start-ups from all over the world have a rare opportunity to keep excelling with innovation as the main capital.

\subsubsection{Research and Development}

Adapting to changes requires money, time and research. It is high time for start-ups to reinvest in research and development. The post Covid world is full of opportunities because the problems in the new world are very different from the old ones. So, the solutions should also be more innovative. 150 million euro is being provided to innovators to face the challenges of the new world, by the European Innovation Council as mentioned by Hynes et al., (2020). The European Institute of Innovation and Technology had orchestrated an association of experts and funds to address the challenges of the post Covid era. There is also the opportunity of specific research fundings made available by the local government.

\subsubsection{The Traditional Supply Chain Management}

Start-up companies have to find a way to replace the traditional supply chain management systems. In most cases businesses have to rely on one single supplier and that is far from ideal. Start-ups need to find out newer sources to get materials. This way the companies will be more flexible, less dependent and the local economies will also flourish. $78 \%$ retailers, wholesalers and manufacturers in Europe have experienced a negative impact on their business. The supply change management is going to determine success or failure in the post corona world. The earlier the new strategies are adopted, the better it is going to be for the start-ups. In 2018 more than $97 \%$ of the batteries used in cars were supplied by Japan, Korea and China as mentioned by Carlesso (2020). In 2020 European commission has set up the Battery Alliance Initiative to encourage more production in Europe.

\subsubsection{Growth}

New domains of challenges and opportunities will keep presenting themselves. Venture capitalists are eager more than ever to invest in ideas. Start-ups should prepare themselves to get used to accepting such challenges.

\section{Methodology}

\subsection{Research Onion}

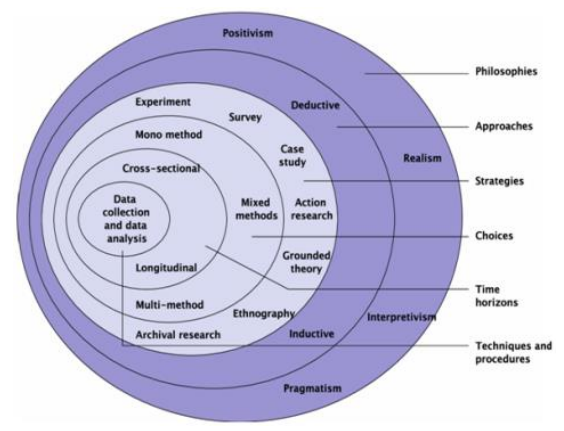

Figure 1. Research onion

Source: Phillips and Moutinho, 2018 
As suggested by Rahmah (2017), a research onion describes different steps that the researcher must go through when constructing a useful methodology. Each layer of the research onion demonstrates a specific method. In this particular research onion, the research philosophy, research approach, and the research design have been undertaken by the researcher to evaluate and analyse the impact of COVID 19 in the European start-ups business and the idea to re-energise the economy Kalogiannidis (2020).

\subsection{Research Philosophy}

According to the study by Long et al., (2018), there are mainly three different kinds of research philosophies used in the methodology of research. They are as follows: 1. Pragmatism, 2. Positivism, and 3. Interpretivism. As suggested by Johnson et al., (2017), Pragmatism is a kind of philosophy that only undertakes and gathers those brand new innovative concepts that are important only if they assist any action. Whereas, Positivism is a kind of philosophy that enables the researchers to be independent and also directs them in creating a research paper that is entirely externalised. Interpretivism is a kind of research philosophy that claims that people are unaffected by external causes of society. In this research paper, the philosophy of Pragmatism has been undertaken by the researcher as it is suitable for examining and analysing the effect of COVID 19 in the European start-ups business and the idea to re-energise the economy.

\subsection{Research Approach}

There are mainly two kinds of approaches used by the researchers in research papers. They are as follows: 1. Deductive and 2. Inductive research approaches. In a Deductive approach, the researcher starts the research with a particular theory and then develops many hypotheses from that theory and after that surveys the information to examine the compromised concept. In an Inductive approach, the researcher begins with a list of considerations that are made on the basis of several facts as suggested by Aquino et al., (2018). In this research paper, the Deductive approach has been undertaken by the researcher because it is apt for evaluating and analysing the effect of COVID 19 in the European start-ups business and the idea to re-energise the economy.

\subsection{Research Design}

There are mainly three kinds of research designs used by the researchers in their research papers. They are as follows: 1. Explanatory, 2. Exploratory, and 3. Descriptive research design. The explanatory design provides a better demonstration of a specific topic. Exploratory design helps in gathering background data of a particular topic. However, a Descriptive design identifies features, frequencies, kinds, impulses, etc of a particular topic as suggested by Rahmah (2017). This research design aims to systematically and accurately narrate a phenomenon, situation, or population. Descriptive research design primarily focuses on evaluating the nature associated with a segment of demographic by not focusing on the reason behind occurring a phenomenon. In this research paper, the Descriptive design has been undertaken by the researcher as it is suitable for examining and analysing the effect of COVID 19 in the European start-ups business and the idea to re-energise the economy Kalogiannidis (2020).

\section{Data Analysis}

\subsection{Thematic Analysis}

Theme 1. Significant challenges in employment in the European start-up business due to COVID 19

In this research paper, it can be observed that due to the COVID 19 pandemic situation, there is a huge amount of unemployment in the start-up industry in Europe. The hiring process is at a stop for a long period of time. This is causing a huge amount of lack in the job section of start-up companies in Europe as suggested by Cunningham (2020). And, also the salary of the existing employees in the start-up industry in Europe has also been reduced. Therefore, it is quite understandable that because of the whole COVID 19 pandemic situation the start-up industry in Europe is going through a tough time and facing huge challenges such as unemployment, decreased hiring process, etc.

Theme 2. Challenges in the establishment of new Start-ups

A considerable amount of problems can be observed in the construction of the new start-ups in Europe due to the COVID 19 pandemic situation. The start-up industry in Europe is running at a loss for a long period of time as suggested by Morales-Narváez and Dincer, (2020). Thus, people who planned to open a new start-up in Europe have to face many economical difficulties. The uncertainty in the economical condition has brought many risks in the opening of new start-ups in Europe.

Theme 3. Interventions of policy to help in the recovery

In the COVID 19 pandemic situation, it can be seen in the start-up industry in Europe that the interventions of policy have the ability to speed up financial recovery. These policies mainly help in solving short term problems such as 
funding, proper conditions, etc as suggested by Tromberg et al., (2020). These policies also help in decreasing boundaries to entrepreneurship and offer proper encouragement. Therefore, it is quite understandable that interventions of policies are essential in the recovery of the start-up industry in Europe.

Table 1. Thematic analysis source: the research

$\begin{array}{lll}\text { Theme 1: Significant } & \text { Theme 2: Challenges in Theme 3: Interventions of } \\ \text { challenges in employment } & \text { the establishment of new } \\ \text { in the European start-up } & \text { Start-ups } & \begin{array}{l}\text { policy to help in the } \\ \text { recovery } \\ \text { business due to COVID 19 }\end{array}\end{array}$

Cunningham, S., (2020). 3 In this research paper, it tips for pharma startup can be observed that due to success. Drug Discovery the COVID 19 pandemic Today. situation, there is a huge amount of unemployment in the start-up industry in Europe.

Morales-Narváez, E., and Dincer, C., (2020). The impact of biosensing in a pandemic outbreak: COVID-19.
A significant amount of In the COVID 19 challenges can be pandemic situation, it can observed in the be observed in the start-up construction of the new industry in Europe that the start-ups in Europe due to interventions of policy the COVID 19 pandemic have the ability to speed situation. up financial recovery.

The start-up industry in These policies mainly help Europe is running at a loss in solving the short term for a long period of time. problems such as funding, Thus, people who planned proper conditions, etc of to open a new start-up in the start-up industry in Europe have to face many Europe. economical difficulties.
Tromberg et al., (2020). The salary of the existing Rapid Scaling Up of employees has also been Covid-19 Diagnostic Testing in the United States-The NIH RADx Initiative. industry in Europe.
The uncertainty in the economical condition has brought many risks in the opening of new start-ups in Europe.
These policies also help in decreasing boundaries to entrepreneurship and offer proper encouragement.

\section{Discussion}

According to the study, the COVID 19 pandemic situation has brought a lot of challenges all over the world. This research paper has shown how it has affected the start-up industry in Europe. There is a huge amount of lack of employment in this industry as suggested by Cunningham (2010). People are losing jobs. There is also a reduction in the salary of the employee who still has jobs. In this pandemic situation not only the existing start-up companies are facing challenges but also there are challenges in the opening of a new start-up due to the financial crisis. However there are several strategies that can help in recovering this entire situation in the start-up industry in Europe as suggested by Tromberg et al., (2020). One of the major strategies is the intervention of policies. These policies will help in the speeding up of the recovery. These policies also help in decreasing boundaries to entrepreneurship and offer proper encouragement.

\section{Conclusion}

\subsection{Conclusion}

As discussed earlier in this research paper, Start-ups have come to be the most essential driving force of economic growth in the last decade. The COVID-19 pandemic has left a devastating economic scene in its path. Thus, it is quite understandable that it has affected the start-up industry in Europe in a vast manner. This research paper has covered all the important effects of the COVID-19 pandemic and the worldwide shutdown on the start-up business operating from Europe. Government's stimulus package effectively works behind reducing some of the effects regarding this pandemic situation. European Commission offered a stimulus package of 750 billion euro as a prevention strategy at the end of May this year. European start up industry has also evaluated the mitigating measures taken by the 
governments to revitalise the economies. It has also discussed and analysed the innovative ideas that might help the start-up industry recover faster. It has also covered the significant challenges in employment in the European start-up business due to COVID-19 and how interventions of policies can help in speeding up the process of recovery in the start-up industry in Europe. Thus, it is quite clear that the COVID-19 pandemic situation has put a lot of negative impact on the start-up industry in Europe. However, with the ideas of new strategies discussed in this research paper, this terrible situation can be recovered.

\subsection{Linking With Objectives}

This research paper has covered all the important impacts of the COVID 19 pandemic and the worldwide shutdown on the start-up business operating from Europe. It has also evaluated and analysed the mitigating measures taken by the governments to revitalise the economies. It has also discussed and analysed the innovative ideas that might help the start-up industry recover faster.

\subsection{Recommendations}

As it can be observed that due to the whole COVID-19 pandemic situation the entire start-up industry in Europe is facing a lot of fundamental challenges, it is very essential to find a remedy for the recovery of this terrible situation. Utilising the Government's stimulus packages is highly recommended. And also the interventions of different policies are recommended to speed up the process of recovery in the start-up industry in Europe. With slogan "Keeping people connected is keeping people safe" during current crisis we need make all the necessary preparation for the post-covid era (Kalogiannidis, 2020).

\subsection{Research Limitations}

Although it is very essential to find new strategies for the recovery of the start-up industry in Europe that has been facing a lot of challenges due to the whole COVID 19 pandemic situation, there is a huge amount of lack in the study on this subject matter. Thus it created a problem for the researchers to collect data on this topic.

\subsection{Future Scope}

There is a good amount of future scope of research on this subject matter as there is a huge lack of information on this topic. Although the situation of the COVID-19 pandemic is new it requires urgent solutions for the recovery of the start-up industry in Europe. This research paper will help future researchers to research this significant subject matter.

\section{References}

Alonso, A. D., Kok, S. K., Bressan, A., O’Shea, M., Sakellarios, N., Koresis, A., ... Santoni, L. J. (2020). COVID-19, aftermath, impacts, and hospitality firms: An international perspective. International Journal of Hospitality Management, 102654. Retrieved from https://www.ncbi.nlm.nih.gov/pmc/articles/PMC7442915/

Aquino, E., Lee, Y. M., Spawn, N., \& Bishop-Royse, J. (2018). The impact of burnout on doctorate nursing faculty's intent to leave their academic position: A descriptive survey research design. Nurse Education Today, 69, 35-40. https://doi.org/10.1016/j.nedt.2018.06.027

Arundale, K., \& Mason, C. (2020). Private equity and venture capital: riding the COVID-19 crisis. Retrieved from https://eprints.gla.ac.uk/221698/1/221698.pdf

Brown, R., Rocha, A., \& Cowling, M. (2020). Financing entrepreneurship in times of crisis: Exploring the impact of COVID-19 on the market for entrepreneurial finance in the United Kingdom. International Small Business Journal, 38(5), 380-390. Retrieved from https://journals.sagepub.com/doi/pdf/10.1177/0266242620937464

Carlesso, M. (2020). Sustainable Banking and Sustainable Living: How to incentivize the Private Sector towards Energy-Efficient Alternatives. Doctoral dissertation.

Chinn, D., Klier, J., Stern, S., \& Tesfu, S. (2020). Safeguarding Europe's livelihoods: Mitigating the employment impact of COVID-19. McKinsey \& Company. Retrieved from https://www.rrhhdigital.com/docs/PRXX_Safeguarding-Europes-livelihoods-Mitigating-the-employment-impac t-of-COVID-19-F.pdf

Cunningham, S. (2020). 3 tips for pharma startup success. Drug Discovery Today. Retrieved from https://www.ncbi.nlm.nih.gov/pmc/articles/PMC7316045/

Donthu, N., \& Gustafsson, A. (2020). Effects of COVID-19 on business and research. Journal of Business Research, 117, 284. Retrieved from https://www.ncbi.nlm.nih.gov/pmc/PMC7280091

Hynes, W., Trump, B., Love, P., \& Linkov, I. (2020). Bouncing forward: a resilience approach to dealing with COVID-19 and future systemic shocks. Environment Systems and Decisions, 1-11. Retrieved from https://www.ncbi.nlm.nih.gov/pmc/articles/PMC7247742/ 
Johnson, R. B., De Waal, C., Stefurak, T., \& Hildebrand, D. L. (2017). Understanding the philosophical positions of classical and neopragmatists for mixed methods research. KZfSS Kölner Zeitschrift für Soziologie und Sozialpsychologie, $\quad 69(2), \quad 63-86 . \quad$ Retrieved $\quad$ from https://scholarworks.iupui.edu/bitstream/handle/1805/16117/Johnson_2017_understanding.pdf?sequence=1

Kalogiannidis, S., \& Mavratzas, S. (2020, December). Impact of marketing mix strategies effective product development issues in MNCs/Retail. International Journal of Business Marketing and Management (IJBMM), 5(12), 118-125.

Kalogiannidis, S. (2020). Covid Impact on Small Business. International Journal of Social Science and Economics Invention, 6(12), 387-391. https://doi.org/10.23958/ijssei/vol06-i12/257

Kalogiannidis, S., \& Melfou, K. (2020). Issues and Opportunities for Agriculture Sector During Global Pandemic. International Journal of Economics, Business and Management Research, 4(12), 204-211.

Kalogiannidis, S. (2020). Impact of Effective Business Communication on Employee Performance. European Journal of Business and Management Research, 5(6). https://doi.org/10.24018/ejbmr.2020.5.6.631

Kalogiannidis, S., Chatzitheodoridis, F., \& Kontsas, S. (2020). An Eclectic Discussion of the Effects of COVID-19 Pandemic on the World Economy During the First Stage of the Spread. International Journal of Financial Research, 11(6), Special Issue, 137-153. https://doi.org/10.5430/ijfr.v11n6p137

Kashyap, A., \& Raghuvanshi, J. (2020). A preliminary study on exploring the critical success factors for developing COVID-19 preventive strategy with an economy centric approach. Management Research: Journal of the Iberoamerican Academy of Management.

Kuckertz, A., Brändle, L., Gaudig, A., Hinderer, S., Reyes, C. A. M., Prochotta, A., ... Berger, E. S. (2020). Startups in times of crisis-A rapid response to the COVID-19 pandemic. Journal of Business Venturing Insights, e00169. Retrieved from https://www.sciencedirect.com/science/article/pii/S2352673420300251

Long, K. M., McDermott, F., \& Meadows, G. N. (2018). Being pragmatic about healthcare complexity: our experiences applying complexity theory and pragmatism to health services research. BMC Medicine, 16(1), 1-9. Retrieved from https://bmcmedicine.biomedcentral.com/articles/10.1186/s12916-018-1087-6

Morales-Narváez, E., \& Dincer, C. (2020). The impact of biosensing in a pandemic outbreak: COVID-19. Biosensors and Bioelectronics, 112274. Retrieved from https://www.ncbi.nlm.nih.gov/pmc/articles/pmc7202811/

Pålsson, Y., Engström, M., Leo Swenne, C., \& Mårtensson, G. (2018). A peer learning intervention targeting newly graduated nurses: A feasibility study with a descriptive design based on the Medical Research Council framework. Journal of Advanced Nursing, 74(5), 1127-1138. Retrieved from https://www.diva-portal.org/smash/record.jsf?pid=diva2:1185060

Rahmah, M. A. (2017). Inductive-Deductive Approach to Improve Mathematical Problem Solving for Junior High School. Journal of Physics: Conference Series, 812(1), 012089. Retrieved from https://iopscience.iop.org/article/10.1088/1742-6596/812/1/012089/pdf

Tromberg, B. J., Schwetz, T. A., Pérez-Stable, E. J., Hodes, R. J., Woychik, R. P., Bright, R. A., ... Collins, F. S. (2020). Rapid Scaling Up of Covid-19 Diagnostic Testing in the United States-The NIH RADx Initiative. New England Journal of Medicine. Retrieved from https://www.nejm.org/doi/full/10.1056/NEJMsr2022263

Woiceshyn, J., \& Daellenbach, U. (2018). Evaluating inductive vs deductive research in management studies. Qualitative Research in Organizations and Management: An International Journal.

Zalaghi, H., \& Khazaei, M. (2016). The role of deductive and inductive reasoning in accounting research and standard-setting. Asian Journal of Finance \& Accounting, 8(1), 23-33.

\section{Copyrights}

Copyright for this article is retained by the author(s), with first publication rights granted to the journal.

This is an open-access article distributed under the terms and conditions of the Creative Commons Attribution license (http://creativecommons.org/licenses/by/4.0/). 